\title{
Vitamin D Deficiency among Patients Visiting a Tertiary Care Hospital: A Descriptive Cross-sectional Study
}

\author{
Nimesh Poudel, ${ }^{1}$ Subodh Sagar Dhakal, ${ }^{1}$ Renu Sukhupayo, ${ }^{1}$ Dambar Bahadur Karki ${ }^{2}$ \\ 'Department of Internal Medicine, Kathmandu Medical College and Teaching Hospital, Sinamangal, Kathmandu, Ne- \\ pal, ${ }^{2}$ Department of Cardiology, Kathmandu Medical College and Teaching Hospital, Sinamangal, Kathmandu, Nepal.
}

\section{ABSTRACT}

Introduction: Vitamin D deficiency is a common condition prevalent among both developed and developing countries where it is seen mostly in females. It has been linked to various skeletal and non-skeletal diseases. This study was done to find out the prevalence of Vitamin D deficiency and clinical features of deficient patients attending the outpatient department of a tertiary care hospital.

Methods: This descriptive cross-sectional study was done among the patients attending the outpatient department of a tertiary care hospital in Kathmandu, Nepal. The study was conducted from May 2019 to July 2019. The ethical approval was taken from the Institutional Review Committee (ref no. 310520113). Convenient sampling was done. The collected data was entered in Microsoft Excel and was analyzed in the Statistical Package for the Social Sciences (SPSS) version 26.

Results: Out of 481 participants, the prevalence of vitamin D deficiency was 335 (69.6\%) (65.49-73.71 at $95 \%$ Confidence Interval). Severe vitamin D deficiency was seen in $78(16.2 \%)$ and insufficient vitamin D in $77(16 \%)$ of the patients. The mean serum vitamin D concentration by gender was $22.38 \pm 17.07 \mathrm{ng} / \mathrm{ml}$ in males and $18.89 \pm 15.25 \mathrm{ng} / \mathrm{ml}$ in females. A total of $263(54.6 \%)$ females and 72 $(14.97 \%)$ males had vitamin D deficiency. The most common symptoms found in vitamin D deficiency patients were fatigue 187 (55.8\%), muscle cramps 131 (39.1\%), generalized myalgia 125(37.31\%), bone and joint pain $111(33.13 \%)$.

Conclusions: Vitamin D deficiency was prevalent especially in females and elderly people. Fatigability was present in more than half of the vitamin $\mathrm{D}$ deficient patients.

Keywords: Nepal; prevalence; vitamin D deficiency.

\section{INTRODUCTION}

Vitamin $D$ is a fat-soluble prohormone, which is involved in the regulation of the physiological processes. ${ }^{1}$ It is found in two forms; ergocalciferol (Vitamin D2) found in plants and fungi, and cholecalciferol (Vitamin D3) from the sun. ${ }^{2}$ Vitamin D deficiency is defined as "25hydroxyvitamin $D$ level of less than 20 ng per millimeter (50nmol per liter)".3,4

It has been estimated that around one billion people have Vitamin D deficiency or insufficiency. ${ }^{5}$ Vitamin D deficiency shows its high prevalence in the developed countries and the regions of Asia, the Middle East, and India mostly in women. ${ }^{6}$ According to several studies, $40-100 \%$ of the US and European population are deficient in Vitamin D. ${ }^{7,8}$ The factors causing Vitamin D deficiency could be due to changes in the lifestyle based on the socio-cultural practice, inadequate sun exposure and the food consumed that are rarely fortified with Vitamin D. ${ }^{9}$ Its deficiency has been linked to different musculoskeletal and non-skeletal complications like congestive heart failure, peripheral vascular disease, hypertension, diabetes mellitus. ${ }^{10}$ So, it is important to know the burden of Vitamin D deficiency for the better patient management.

Correspondence: Dr. Nimesh Poudel, Department of Internal Medicine, Kathmandu Medical College and Teaching Hospital, Sinamangal, Kathmandu, Nepal. Email: nimpoudel@yahoo.com, Phone: +977-9841502372 
The present study is done to find out the occurrence of vitamin $D$ deficiency and the frequency of clinical features of vitamin $D$ deficient patients.

\section{METHODS}

This descriptive cross-sectional study was done among patients attending the outpatient department (OPD) and general health checkup of Kathmandu Medical College and Teaching Hospital, Kathmandu, Nepal. The study was conducted from May 2019 to July 2019. The ethical approval was taken from the Institutional Review Committee of the Kathmandu Medical College and Teaching Hospital (ref no. 310520113). Patients visiting the OPDs were included in the study. Patients under the age of 15 years, those with chronic kidney disease and on medication that affects bone metabolism like phenobarbital, anti-tubercular drugs, thiazide, antiretroviral, glucocorticoids, and Vitamin D treatment for Vitamin $D$ deficiency were excluded from the study. Informed written consent was taken from the participants. Convenient sampling was done. The sample size was calculated by using the formula,

$n=Z^{2} \times p \times(1-p) / e^{2}$

$=(1.96)^{2} \times(0.5) \times(1-0.5) /(0.07)^{2}$

$=196$

Where,

$\mathrm{n}=$ required sample size

$Z=1.96$ at $95 \%$ Confidence Interval,

$p=$ population proportion, $50 \%$

$\mathrm{e}=$ margin of error, $7 \%$

As patients were enrolled using the convenient sampling, we doubled the size and considering $20 \%$ non-respondent rate, the total sample of 481 patients was taken for measurement of vitamin $D$.

Data collected in semi-structured questionnaire regarding demographics, clinical features like fatigue, body ache, muscle cramps, joint pain, low backache, and medical history of diabetes, hypertension, chronic kidney disease, and Ischemic heart diseases (IHDs). Body mass index was used to define the weight status. Serum Vitamin D3, which is 25 hydroxyvitamin D [25(OH) D], was estimated by a fully-automated chemiluminescence immunoassay.

Vitamin D deficiency was defined as $25(\mathrm{OH})$ D less than $20 \mathrm{ng} / \mathrm{ml}$, Vitamin D insufficiency as $20-29 \mathrm{ng} / \mathrm{ml}$, and Vitamin D sufficiency as $\geq 30 \mathrm{ng} / \mathrm{ml}$, and Vitamin D toxicity as more than $100 \mathrm{ng} / \mathrm{ml}$. Vitamin $D$ levels less than $10 \mathrm{ng} / \mathrm{ml}$ were regarded as a severe deficiency. ${ }^{2,11}$
The data collected was entered in Microsoft Excel and was analyzed in the IBM Statistical Package of the Social Sciences (SPSS) version 26. Demographic data and clinical variables were analyzed by descriptive analysis. Results are expressed as mean \pm standard deviation for quantitative variables and percentage for qualitative variables like symptoms.

\section{RESULTS}

A total of 481 participants were included in the study. Overall, vitamin D deficiency was found in 335 $(69.6 \%)(65.49-73.71$ at $95 \%$ Confidence Interval). Insufficiency was seen in $77(16 \%)$ patients. Among the participants, $69(14.3 \%)$ had the sufficient vitamin $D$ levels (Table 1) The total mean age of the participants was $40.5 \pm 14.4$ years $(39.64 \pm 14.10$ for females and $43.59 \pm 15.13$ for males). The majority were females with a female: male ratio of $3.3: 1$. The study included $111(23.1 \%)$ males and $370(76.1 \%)$ females.

\begin{tabular}{|ll|}
\hline \multicolumn{2}{|l|}{ Table 1. Vitamin D status in patients. } \\
\hline Vitamin D levels $(\mathbf{n g} / \mathrm{ml})$ & Frequency $\mathbf{n}(\%)$ \\
Deficiency $(<20)$ & $335(69.6)$ \\
$\begin{array}{l}\text { Insufficiency }(\geq 20 \\
-<30)\end{array}$ & $77(16)$ \\
Sufficiency $(\geq 30)$ & $69(14.3)$ \\
Total & $481(100)$ \\
\hline
\end{tabular}

The total mean serum vitamin $D$ was $19.69 \pm 13.68 \mathrm{ng} /$ $\mathrm{ml}$. The mean serum vitamin $\mathrm{D}$ concentration by gender was $22.38 \pm 17.07 \mathrm{ng} / \mathrm{ml}$ in males and $18.89 \pm 15.25 \mathrm{ng} /$ $\mathrm{ml}$ in females.

In the study, out of 481 participants, $78(16.2 \%)$ of the participants had severe vitamin D deficiency. Among severely vitamin D deficient patients, 59 (75.6\%) were symptomatic. The most common symptoms among them were fatigability 44 (56.4\%), generalized myalgia $41(52.6 \%)$, bone and joint pain 35 (44.9\%), and muscle cramps 37 (47.4\%). Among 257 mild vitamin D deficient patients, 169 (65.8\%) participants had symptoms. The symptoms among them were fatigability 143 (55.6\%), muscle cramps 94 (36.6\%), generalized myalgia 84 $(32.7 \%)$, bone and joint pain in 76 (29.6\%). Overall, $227(68.05 \%)$ of vitamin D deficient patients were symptomatic. Vitamin D deficient patient includes mild and severe vitamin D deficiency. The symptoms among vitamin D deficient were fatigability 187 (55.8\%), muscle cramps 131 (39.1\%), generalized myalgia 125 $(37.31 \%)$, bone and joint pain 111 (33.13\%). The symptoms were predominantly seen in patients with severe deficiency. Some patients with severe deficiency also have a history of hair fall (Table 2 ). 
Poudel et al. Cross-sectional Study on Vitamin D Deficiency among Patients Visiting a Tertiary Care Hospital

\begin{tabular}{|c|c|c|}
\hline Symptoms & $\begin{array}{l}\text { Severe } \quad \text { Deficiency } \\
(n=78) \text { n }(\%)\end{array}$ & $\begin{array}{l}\text { Deficiency } \\
(n=335) \text { n (\%) }\end{array}$ \\
\hline Fatigability & $44(56.4)$ & $187(55.8)$ \\
\hline $\begin{array}{l}\text { Generalized } \\
\text { Myalgia }\end{array}$ & $41(52.6)$ & $125(37.31)$ \\
\hline Muscle cramps & $35(44.9)$ & $131(39.1)$ \\
\hline $\begin{array}{l}\text { Bone and joint } \\
\text { pain }\end{array}$ & $37(47.4)$ & $111(33.13)$ \\
\hline
\end{tabular}

A total of $263(54.6 \%)$ females and $72(14.97 \%)$ males had vitamin D deficiency (Table 3 ).

\begin{tabular}{|c|c|c|c|}
\hline \multicolumn{4}{|c|}{$\begin{array}{l}\text { Table 3. Status of Vitan } \\
\text { females }(n=481)\end{array}$} \\
\hline & & \multicolumn{2}{|c|}{ Gender } \\
\hline & & Male n (\%) & Female $n(\%)$ \\
\hline \multirow{3}{*}{$\begin{array}{l}\text { Vitamin D } \\
\text { levels in } \\
\mathrm{ng} / \mathrm{ml}\end{array}$} & $<20$ & 72 (15.0) & 263 (54.7) \\
\hline & $\begin{array}{l}>20 \\
<30\end{array}$ & $15(3.1)$ & 62 (12.9) \\
\hline & $\geq 30$ & $24(5.0)$ & $45(9.4)$ \\
\hline
\end{tabular}

Seventy-six $(22.7 \%)$ of patients with vitamin D deficiency were between the 66-75 aged group followed by $36-45$ aged groups with 68 (20.3\%) patients, 26-35 aged groups with $63(18.8 \%)$ patients, and $46-55$ aged groups with $57(17 \%)$ patients. The age group with the least number of patients with vitamin $D$ deficiency was between 15-25 aged groups with 9 (1.87\%).

\section{DISCUSSION}

The results of this cross-sectional study done in a tertiary care hospital of Kathmandu, Nepal showed the prevalence of Vitamin D deficiency as 69.6\%, of insufficiency as $16 \%$, and sufficient Vitamin D in $14.3 \%$. The prevalence was higher among older ages and females. A severe deficiency was seen in $16.2 \%$ of the studied population. The rates of Vitamin D deficiency found in this study are markedly higher than in many western countries like in Germany, Austria, and the Netherlands, in North Europe (Denmark, Finland, Ireland, and Poland), Canada, and the United Kingdom which have shown the prevalence of vitamin D deficiency from $10-55.5 \% .{ }^{11-12}$

Mariam Omar et al. reported a deficiency of $76.1 \%$ and insufficiency of $15.2 \%$ among the population of Benghazi, a sunny second-largest city in the east of Libya. $^{2}$ Our results share similar vitamin $D$ deficiency status with some parts of Africa, Asia, and the Middle East. The prevalence of vitamin D deficiency in Egypt was $77 \%$, insufficiency was $15 \%$, and $9 \%$ of the population has sufficient Vitamin D levels. In Qatar, 83$91 \%$ of the population is deficient in Vitamin D. 2,13
Vitamin D deficiency is considered to be a public health problem worldwide. Female gender is one of the most important predictors of vitamin D deficiency. ${ }^{2}$ In this study, $23.1 \%$ of the participants were males and $76.1 \%$ were females. Out of the studied population, $54.7 \%$ of the females and $15 \%$ of the males had vitamin D deficiency. This finding of increased prevalence seen in females is comparable to other studies and can be due to a sedentary lifestyle and aggressive sun protection. The greater participation of females in the studies may be due to the greater willingness of females to use health services. ${ }^{2}$ Babita Ghai et al. reported $73 \%$ of the female to be vitamin D deficient. ${ }^{14}$ In contrast, Manoharan et al. studied the vitamin D status among people of Tamil Nadu and reported that $46 \%$ of the males and $37 \%$ of the females had a vitamin $D$ deficiency. ${ }^{15}$

Vitamin D deficiency was seen in $22.7 \%$ of patients between the $66-75$ aged group and $20.3 \%$ in the 36 45 age group and $17 \%$ in $46-55$ aged group patients. Various studies report a similar observation by demonstrating lower vitamin $D$ levels with increasing ages and higher vitamin D deficiency states in the older age group, mandating early investigating and thus helping them to prevent falls and fractures. ${ }^{2,16}$

In the study, it was found that among the 335 vitamin D deficient patients, $228(68.05 \%)$ of the participants had symptoms. The most common symptoms that led the participant to seek health services were fatigue, generalized myalgia, and bone pain. Fatigability was seen in $55.8 \%$, muscle cramps in $39.1 \%$, generalized myalgia in $39.1 \%$, bone and joint pain in $33.13 \%$ of the vitamin $D$ deficient patients. The symptoms were predominantly seen in patients with severe deficiency. Lubna $\mathrm{M}$ et al, in their study, showed that the most common reason for requesting vitamin $\mathrm{D}$ level included generalized myalgia and bone pain in $51 \%$ of the patients. ${ }^{17}$ Satyajeet Roy et al. showed the prevalence of low vitamin in inpatients as $77.2 \%$ with fatigue and fatigability was normalized after correction of vitamin D level. ${ }^{18}$

Our study has demonstrated a high prevalence of vitamin $D$ deficiency among patients visiting in our center. A larger multicentric or community based study with a diverse sample population should be conducted in the future to find out a more accurate prevalence. Similarly, other studies that further look into the association between gender and age and other comorbidities with vitamin D levels in Nepalese are warranted.

\section{CONCLUSIONS}

Vitamin D deficiency was prevalent especially in females and elderly people. Fatigability was present in more than half of the vitamin $D$ deficient 
patients. Muscle cramps and generalized myalgia were present in more than one third and bone and joint pain in almost one third of the vitamin D deficient patients.

\section{Conflict of Interest: None.}

\section{| Full Text $\mid \underline{\text { DOI] }}$}

10. Holick MF. Vitamin D deficiency. N Engl J Med. 2007 Jul 19;357(3):266-81. [PubMed | Full Text | DOI]

11. G R, Gupta A.Vitamin D deficiency in India: prevalence, causalities and interventions. Nutrients. $2014 \mathrm{Feb}$ 21;6(2):729-75. [PubMed | Full Text | DOI]

12. Russ TC, Murianni L, Icaza G, Slachevsky A, Starr JM. Geographical Variation in Dementia Mortality in Italy, New Zealand, and Chile: The Impact of Latitude, Vitamin $\mathrm{D}$, and Air Pollution. Dement Geriatr Cogn Disord. 2016;42(1-2):31-41. [uuMed | Full Text | DOI]

13. Badawi A, Arora P, Sadoun E, Al-Thani AA, Al Thani MH. Prevalence of vitamin D insufficiency in Qatar: A systematic review. J Public Health Res. 2012 Dec 28;1(3):229-35. [PubMed | Full Text | DOI]

14. Ghai B, Bansal D, Kapil G, Kanukula R, Lavudiya S, Sachdeva N. High Prevalence of Hypovitaminosis D in Indian Chronic Low Back Patients. Pain Physician. 2015;18(5):E853-62. [PubMed | Full Text]

15. Manoharan A, Selvaraj P, Vasanthamani P. Vitamin D level among patients with nonspecific musculoskeltal pain attending tertiary care hospital in Tamil Nadu. International Journal of Orthopaedics Sciences. 2016:2(4):94-96. [Full Text | DOI]

16. Hilger J, Friedel A, Herr R, Rausch T, Roos F, Wahl DA, et al. A systematic review of vitamin D status in populations worldwide. Br J Nutr. 2014 Jan 14;111(1):23-45. [PubMed | $\underline{\text { Full Text }} \mid \underline{\text { DOI] }}$

17. Zuberi LM, Habib A, Haque N, Jabbar A. Vitamin D Deficiency in ambulatory patients. J Pak Med Assoc. 2008 Sep;58(9):482-4. [ PubMed | Full Text ]

18. Roy S, Sherman A, Monari-Sparks MJ, Schweiker O, Hunter K. Correction of Low Vitamin D Improves Fatigue: Effect of Correction of Low Vitamin D in Fatigue Study (EViDiF Study). N Am J Med Sci. 2014 Aug;6(8):396-402. [uuMed | Full Text | DOI]

(c) The Author(s) 2018.

This work is licensed under a Creative Commons Attribution 4.0 International License. The images or other third party material in this article are included in the article's Creative Commons license, unless indicated otherwise in the credit line; if the material is not included under the Creative Commons license, users will need to obtain permission from the license holder to reproduce the material. To view a copy of this license, visit http://creativecommons.org/licenses/by/4.0/ 